\title{
ПСИХОЛОГИЧЕСКОЕ БЛАГОПОЛУЧИЕ РОССИЙСКИХ И АРМЯНСКИХ СТУДЕНТОВ: КРОССКУЛЬТУРНЫЙ АСПЕКТ
}

\author{
Исследование выполнено при финансовой поддержке РФфИ и КН РА в \\ рамках научного проекта \\ № 20-513-05005 20. \\ Шипова Н.С., Румянцев Ю.В., Самохвалова А. Г. (Костромской \\ государственный университет, Кострома, Россия) \\ ronia_777@mail.ru; rum_kpn@mail.ru; a_samohvalova@ksu.edu.ru

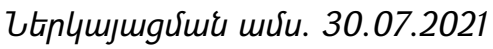

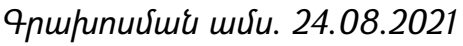

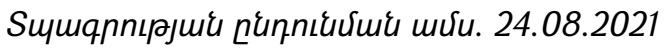

В настоящей статье представлены результаты эмпирического анализа компонентов счастья и благополучия в соответствии с теоретической и частично эмпирически верифицированной авторской моделью. Описаны результаты дескриптивной статистической обработки данных 363 респондентов, а также факторного анализа данных счастья и благополучия в двух выборках: российских и армянских студентов. Также описано сравнение данных показателей. В результате выделены различные представления о психологическом благополучии, существующие в среде студенческой молодежи. При наличии сходств в рассмотрении благополучия как результата и цели деятельности (фактор «Благополучие как результат /деятельность»), а также образа будущего (фрактор «Благополучие как цель»), к которому стремится человек, студенты разных национальностей закладывают различные представления в этот образ. Россияне сочетают семейное, личностное и профессиональное благополучие более органично, чем армяне. При этом армяне лучше интегрируют успешность в межличностном и внутриличностном взаимодействии, в то время, как российские студенты склонны эти параметры разделять. В целом, статья иллюстрирует схожесть количественных показателей психологического благополучия и счастья у российский и армянских студентов при разном качественном наполнении исследуемых показателей.

Ключевые слова: психологическое благополучие, студенческий возраст, счастье, удовлетворенность жизнью, смысложизненные ориентации, типология.

DOI: https://doi.org/10.46991/SBMP/2021.4.2.303

Вопрос психологического благополучия не теряет своей актуальности уже многие десятилетия. Наука вплотную подошла к структурированию изучаемых 
феноменов. Ключевым понятием нашего исследования выступает психологическое благополучие субъекта, которое понимается нами как интегральная характеристика состояний человека, обеспечивающих согласованность психических функций и процессов, достижение внутреннего равновесия и субъектной целостности. Результаты теоретического анализа многочисленных исследований как классической, так и современной психологии, позволили нам сделать вывод о том, что психологическое благополучие реализуется на психофизиологическом, индивидуальнопсихологическом и социально-психологическом уровнях. О.Н. Фомина выявила внутренние фракторы, обеспечивающие психологическое благополучие: компоненты, связанные с управлением средой и автономностью поведения; афрфективные и защитные компоненты; регулятивные компоненты; интерперсональные компоненты; компоненты социальной направленности [4]. Е.Ю. Григоренко интересовал вес факторов общего психологического благополучия в зависимости от курса обучения. Выяснилось, что ярче выражены фракторы, связанные с личностным ростом и позитивными отношениями с окружением, а слабее выражен фактор управления средой [1]. Также в фокусе внимания ученых находятся кросскультурные различия данного параметра. При кросскультурном сравнении социальных представлений о благополучии, О.С. Машарская сделала вывод, что общими фракторами в структуре представлений студентов являются удовлетворенность проведением досуга, отношениями с друзьями, значимость материального положения, альтруизм, позитивная оценка будущего, при этом характер взаимосвязи общих фракторов структуры социальных представлений о благополучии различается в зависимости от национальности респондентов (Россия, Соединенные Штаты Америки, Белоруссия). Автором была обнаружена зависимость кросскультурных различий в структуре социальных представлений о благополучии от значимости сфреры жизни (семейная жизнь, профессиональная деятельность, сфера обучения и образования), социального влияния (следование социальным требованиям, положение в обществе, сохранение индивидуальности), оценки здоровья (физического и психологического), саморазвития, духовного удовлетворения, отношения к прошлому и настоящему [2].

Проведенный Е.Ю. Чеботаревой (2018) сравнительный анализ уровней психологического благополучия российских и французских студентов доказал различия в большинстве аспектов психологического благополучия: В показателях позитивных отношений, управления средой, осознанности жизненных целей и самопринятия фрранцузские студенты показали более высокие результаты. Российские студенты демонстрируют более высокие показатели только по шкале личностного роста. При этом обе группы достаточно высоко удовлетворены собственной автономией. Это позволяет автору сделать вывод 
о связи уровня психологического благополучия с принадлежностью к определенной культуре [5].

Нами проведено исследование с целью проверки возможности экстраполяции данного суждения на иные группы. Для кросскультурного сравнения нами были выбраны две группы: российских (183 человека, из них $8,2 \%$ - юноши, 91,8\% - девушки; $M=20,11 ; \mathrm{SD}=3,07)$ и армянских студентов (180 человек, из них 11,7\% - юноши и 88,3\% - девушки; $M=20,25 ; \mathrm{SD}=3,35)$. Российские респонденты являются студентами Костромского государственного университета, армянские студенты обучаются в Ереванском государственном университете. Выборку составили обучающиеся разных направлений подготовки (гуманитарного, педагогического, инженерно-технического, естественнонаучного).

Методический инструментарий соответствует авторской модели психологического благополучия студентов. Он состоит из следующих тестовых методик: Шкала субъективного счастья (С. Любомирски, Х. Леппер, а адаптации Леонтьева Д.А., 2013), Шкала психологического благополучия Риффр, RPWB, 1989; в адаптации Н. Н. Лепешинского (2007), Шкала удовлетворенности жизнью (Satisfaction With Life Scale - SWLS) (E.Diener, R.A. Emmons, R.J. Larsen, S. Griffin, 1985; адаптация и валидизация Д.А. Леонтьева и Е.Н. Осина, 2003), тест «Смысложизненные ориентации (СЖО)» Д.А. Леонтьева, 2000; экспрессметодика "Инновационность и адаптивность» (Altkirt) M. Babic, E. College, Е. Davis, R. Cunningham, 1999; тест «Оценка микроклимата студенческой группы». B.M. Завьяловой, 2002.

Обработка данных проводилась в программе SPSS Statistics 20.0. Нами были применены методы дескриптивной статистики и факторый анализ.

Таблица 1.

Данные дескриптивной статистики исследуемых переменных (по шкалам стандартизированных методик)

\begin{tabular}{|l|c|c|c|c|}
\hline \multirow{2}{*}{ Показатели } & \multicolumn{2}{|c|}{$\begin{array}{c}\text { Российские } \\
\text { студенты }\end{array}$} & \multicolumn{2}{c|}{$\begin{array}{c}\text { Армянские } \\
\text { студенты }\end{array}$} \\
\cline { 2 - 5 } & $\mathrm{M}$ & $\mathrm{SD}$ & $\mathrm{M}$ & $\mathrm{SD}$ \\
\hline $\begin{array}{l}\text { Интегральный показатель удовлетворенности } \\
\text { жизнью* }\end{array}$ & 4,85 & 1,64 & 4,37 & 1,68 \\
\hline $\begin{array}{l}\text { Переживание счастья* } \\
\text { Общий показатель благополучия*** }\end{array}$ & 18,67 & 4,64 & $\begin{array}{c}19,3 \\
7\end{array}$ & $\begin{array}{c}4,4 \\
4\end{array}$ \\
\hline Положительные отношения с другими*** & 3,23 & 1,80 & 3,22 & 1,57 \\
\hline Личностный рост & 3,65 & 1,73 & 3,73 & 1,81 \\
\hline
\end{tabular}




\begin{tabular}{|c|c|c|c|c|}
\hline Автономия*** & 3,9 & 2,3 & 4,07 & 1,93 \\
\hline Управление окружением ${ }^{* * *}$ & 3,14 & 1,74 & 2,89 & 1,57 \\
\hline Самопринятие & 3,75 & 1,88 & 3,53 & 1,63 \\
\hline Цели в жизни*** & 3,30 & 1,81 & 3,7 & 1,65 \\
\hline Инновационная компетентность ${ }^{* * * *}$ & 3,8 & 1,85 & 3,91 & 1,71 \\
\hline
\end{tabular}

Примечания: M - среднее значение, SD - стандартное отклонение;

*Шкала удовлетворенности жизнью; **Шкала субъективного счастья; ***Шкала психологического благополучия; ****Инновационность и адаптивность».

В приведенной таблице мы видим очень схожие значения по основным параметрам психологического благополучия в изучаемых группах студентов. Это может говорить как о схожести установок и представлений о благополучном человеке в целом, так и о схожем уровне жизни представителей разных национальностей, представленных в нашей выборке. При этом, можно отметить, что показатели субъективного благополучия студентов находятся в пределах нормативных значений для данной возрастной группы.

На следующем этапе исследования нами был проведен фракторный анализ данных, полученных в обеих группах респондентов. При анализе российской выборки нами было выделено 5 факторов, армянской - 4 фактора. В таблице 2 представлены переменные, составляющие типы психологического благополучия студентов двух групп. Следует отметить, что факторы по армянской выборке расположены не в порядке снижения общего веса, а в логике схожести наполняемости факторов определенными переменными в двух выборках.

Таблица 2

Факторы психологического благополучия российских и армянских

студентов

\begin{tabular}{|l|l|l|l|}
\hline \multicolumn{2}{|c|}{ Российские студенты } & \multicolumn{2}{c|}{ Армянские студенты } \\
\hline \multicolumn{2}{|c|}{ Переменные } & \multicolumn{1}{c|}{ Пначененные } & Значение \\
\hline фактор (общий вес фактора 10,45) & 1 фактор (общий вес фактора 3,86) \\
\hline Стремление к счастью & 0,79 & & \\
Семья & 0,78 & & \\
Каким я хочу быть & 0,73 & & \\
Любовь & 0,71 & & 0,77 \\
Достижения & 0,67 & & 0,71 \\
Здоровье & 0,65 & & 0,53 \\
Мое будущее & 0,65 & Мое будущее & \\
Радость & 0,62 & Счастье & \\
Какой я есть & 0,61 & & \\
\hline
\end{tabular}




\begin{tabular}{|c|c|c|c|}
\hline $\begin{array}{l}\text { Интересное занятие } \\
\text { Развитие } \\
\text { Мое настоящее } \\
\text { Успех } \\
\text { Статус } \\
\text { Знания }\end{array}$ & $\begin{array}{l}0,61 \\
0,59 \\
0,59 \\
0,53 \\
0,52 \\
0,49\end{array}$ & $\begin{array}{l}\text { Образ Я (каким я хочу } \\
\text { быть) } \\
\text { Радость } \\
\text { Общение } \\
\text { Здоровье } \\
\text { Любовь } \\
\text { Успех }\end{array}$ & $\begin{array}{l}0,44 \\
0,40 \\
0,37 \\
0,33 \\
0,31\end{array}$ \\
\hline $\begin{array}{l}\text { Моя учеба } \\
\text { Деньги }\end{array}$ & $\begin{array}{l}0,47 \\
0,46\end{array}$ & & \\
\hline \multicolumn{2}{|c|}{2 фактор (общий вес фактора 7,96) } & \multicolumn{2}{|c|}{2 фактор (общий вес фактора 3,6) } \\
\hline $\begin{array}{l}\text { Осмысленность жизни } \\
\text { Локус контроля Жизнь } \\
\text { Процесс жизни } \\
\text { Результат } \\
\text { Локус контроля Я } \\
\text { Цели в жизни } \\
\text { Удовлетворенность } \\
\text { жизнью } \\
\text { Общий показатель } \\
\text { благополучия } \\
\text { Счастье } \\
\text { Инновационная } \\
\text { компетентность }\end{array}$ & $\begin{array}{l}0,95 \\
0,93 \\
0,90 \\
0,89 \\
0,89 \\
0,89 \\
0,77 \\
0,74 \\
0,68 \\
-0,29\end{array}$ & $\begin{array}{l}\text { Оценка уровня } \\
\text { собственного благополучия } \\
\text { Итоговая сумма счастья } \\
\text { Оценка состояния своего } \\
\text { здоровья } \\
\text { Уровень дохода } \\
\text { Наличие собственной } \\
\text { жилплощади } \\
\text { Степень } \\
\text { удовлетворенности } \\
\text { построением близких } \\
\text { отношений } \\
\text { Статус } \\
\text { Управление }\end{array}$ & $\begin{array}{l}0,70 \\
0,43 \\
0,44\end{array}$ \\
\hline \multicolumn{2}{|c|}{3 фактор (общий вес фактора 6,59) } & \multicolumn{2}{|c|}{3 фактор (общий вес фактора 8,19) } \\
\hline $\begin{array}{l}\text { Коммуникабельность } \\
\text { Активность } \\
\text { Способность работать в } \\
\text { команде } \\
\text { Склонность к лидерству и } \\
\text { руководству } \\
\text { Креативность } \\
\text { Открытость новому опыту } \\
\text { Готовность к изменениям } \\
\text { Целеустремленность } \\
\text { Жизнестойкость } \\
\text { Исполнительность } \\
\text { Успех } \\
\text { Общение } \\
\text { Положительные } \\
\text { отношения с другими }\end{array}$ & $\begin{array}{l}0,76 \\
0,71 \\
0,69 \\
0,68 \\
0,60 \\
0,53 \\
0,49 \\
0,46 \\
0,41 \\
0,29 \\
0,18 \\
0,15 \\
0,15 \\
0,13 \\
0,12 \\
0,12\end{array}$ & $\begin{array}{l}\text { Исполнительность } \\
\text { Способность работать в } \\
\text { команде } \\
\text { Жизнестойкость } \\
\text { Активность } \\
\text { Креативность } \\
\text { Готовность к изменениям } \\
\text { Склонность к лидерству и } \\
\text { руководству } \\
\text { Целеустремленность } \\
\text { Ответственность } \\
\text { Коммуникабельность } \\
\text { Открытость новому опыту } \\
\text { Внешний контроль } \\
\text { (контроль ситуации) } \\
\text { Самоэффективность }\end{array}$ & $\begin{array}{l}0,73 \\
0,74 \\
0,79 \\
0,69 \\
0,65 \\
0,49 \\
0,55\end{array}$ \\
\hline
\end{tabular}




\begin{tabular}{|c|c|c|c|}
\hline $\begin{array}{l}\text { Мое настоящее } \\
\text { Управление окружением } \\
\text { Моя профессия }\end{array}$ & & & \\
\hline \multicolumn{2}{|c|}{4 фактор (общий вес фактора 2,53) } & \multicolumn{2}{|c|}{4 фактор (общий вес фактора 6,01) } \\
\hline $\begin{array}{l}\text { Автономия } \\
\text { Личностный рост } \\
\text { Цели в жизни } \\
\text { Самопринятие } \\
\text { Какой я есть } \\
\text { Климат группы }\end{array}$ & $\begin{array}{l}0,72 \\
0,59 \\
0,44 \\
0,37 \\
0,21 \\
-0,19\end{array}$ & $\begin{array}{l}\text { Управление окружением } \\
\text { Личностный рост } \\
\text { Цели в жизни } \\
\text { Самопринятие } \\
\text { Общий показатель } \\
\text { благополучия } \\
\text { Положительные отношения } \\
\text { с другими } \\
\text { Автономия } \\
\text { Удовлетворенность жизнью }\end{array}$ & $\begin{array}{l}0,77 \\
0,76 \\
0,81 \\
0,77 \\
0,97 \\
0,69 \\
0,65 \\
0,57\end{array}$ \\
\hline \multicolumn{2}{|c|}{5 фактор (общий вес фактора 1,79) } & \multicolumn{2}{|l|}{-} \\
\hline $\begin{array}{l}\text { Внутренний контроль } \\
\text { Внешний } \quad \text { контроль } \\
\text { (контроль ситуации) } \\
\text { Самоэффективность }\end{array}$ & $\begin{array}{l}0,75 \\
0,57 \\
0,46\end{array}$ & \multicolumn{2}{|l|}{-} \\
\hline
\end{tabular}

При анализе факторов, выявленных на российской выборке, нами даны следующие обозначения:

- Первый фрактор, который мы назвали "Благополучие как цель», подчеркивает взаимосвязь счастья и внутренней гармонии с многочисленными мотивационно-потребностными показателями, к которым субъект стремится как к образу желаемого благополучного будущего.

- Второй фактор - «Благополучие как деятельность» - включает такие переменные как счастье, благополучие и удовлетворенность жизнью, которые представляют актуальное, деятельностное состояние субъекта и описывают характеристики активности личности, направленные на достижение целей, составляющих благополучную, наполненную жизнь.

- В третьем фракторе - «Благополучие как взаимодействие» - самые высокие нагрузки имеют показатели, относящиеся к сорере общения, социального взаимодействия и социальной активности личности.

- Четвертый фрактор - «Благополучие как автономность» - отражает низкую мотивированность субъекта на социальное взаимодействие и активную деятельность, высокую сконцентрированность на себе, ценность своей индивидуальности, независимости.

- В пятом факторе - «Благополучие как контроль» - большую нагрузку имеют переменные контроля и саморегуляции, что отражает высокую 
ориентированность субъекта на строгое соответствие его деятельности социальным нормам.

Факторы, полученные при анализе выборки армянских студентов, нами обозначены таким образом:

- Первый фрактор назван нами «Благополучие как цель» (общая дисперсия 4,14; доля общей объясненной дисперсии 0,06), поскольку в нем представлены интенции и желания субъекта, образ благополучного будущего, к которому он стремится. Сюда входят эмоционально насыщенные маркеры субъективного благополучия при отсутствии реальной деятельности, направленной на достижение счастья.

- Второй фрактор получил название "Благополучие как успешность» (общая дисперсия 3,17; доля общей объясненной дисперсии 0,046), поскольку в большей степени он представлен стереотипными представлениями о благополучном субъекте как о человеке, добившемся определенных статусных вещей. Сюда входят «объективные» показатели благополучия: жилплощадь, доход, наличие романтических отношений, наличие социального статуса, возможность управлять другими людьми.

- Третий фрактор, обозначенный нами «Благополучие как результат» (общая дисперсия 6,41; доля общей объясненной дисперсии 0,09), отражает в большей степени компоненты и характеристики деятельности, надлежащее выполнение которой приведет к успеху и отличному результату. Субъект видит благополучие как конкретный результат, как эффект деятельности, которой он занимается, поэтому компонентами благополучия в данном случае будут являться характеристики самой личности, имеющие отношение к деятельности и взаимодействию в команде. Характерно, что напрямую параметр благополучия и счастья в этом факторе не представлен, однако, опираясь на субъектно-деятельностный подход, мы можем рассматривать данные параметры как предикторы удовлетворенности субъекта собой, выполняемой деятельностью и жизнью в целом.

- Четвертый фрактор обозначен нами как "Благополучие как гармония» (общая дисперсия 5,92; доля общей объясненной дисперсии 0,086), поскольку он включает в себя компоненты, относящиеся к эффективному социальному взаимодействию, установлению положительных отношений с окружающими, что обеспечивает гармонию субъекта в социокультурном контексте; а также готовность студентов к личностному росту, самопознанию и самопринятию, что обеспечивает внутреннюю гармонию личности.

Сопоставление результатов фракторного анализа в двух выборках свидетельствует о некотором расхождении представлений о счастье и психологическом благополучии у представителей разных национальностей, что противоречит данным дескриптивной статистики, представленной выше. При 
этом, поскольку факторный анализ является более точным и углубленным методом анализа данных, мы склонны в большей степени ориентироваться на полученные при помощи него результаты, констатируя наличие кросскультурных различий психологического благополучия российских и армянских студентов. Однако мы признаем необходимость расширения выборки и подключения качественных методов исследования в ходе дальнейшего изучения проблематики.

Первые фракторы в двух выборках нами обозначены одинаково "Благополучие как цель», поскольку включают схожие компоненты, однако в российском варианте большее количество элементов, которые направлены на семейную, личную и профессиональную сферы. В армянском варианте профессиональная сфрера как цель не представлена. Это может объясняться большей ориентацией студентов именно на сферу семейных и личных отношений, особенно учитывая, что большая часть выборки - женская, что соответствует традиционным культурным представлениям о счастье для армянских девушек [3].

Также схожими являются компоненты третьих фракторов («Благополучие как взаимодействие» в российской выборке и "Благополучие как результат» в армянской выборке). Однако, не смотря на общую ориентированность студентов на достижение конкретного результата, в российской выборке в данный фрактор входят еще и показатели общения, установления социальных взаимоотношений, тогда как в армянской выборке межличностный, интерактивный аспект отсутствует. При этом аспекты взаимодействия как детерминанты психологического благополучия в армянской выборке выделены в отдельный фрактор, что также свидетельствует о культурных различиях, связанных со спецификой общения, межличностного взаимодействия и их роли в субъективном ощущении психологического благополучия, в установлении внутренней и внешней гармонии личности.

Таким образом, в результате факторного анализа данных российской и армянской выборки, нами выделены различные представления о психологическом благополучии, существующие в среде студенческой молодежи, а также описана кросскультурная специфика типов психологического благополучия. При наличии сходств в рассмотрении благополучия как результата и цели деятельности, а также образа будущего, к которому стремится человек, студенты разных национальностей закладывают различные представления в этот образ. Россияне сочетают семейное, личностное и профрессиональное благополучие более органично, чем армяне. При этом армяне лучше интегрируют успешность в межличностном и внутриличностном взаимодействии, при том, что российские студенты склонны эти параметры разделять. Таким образом, нами отмечена схожесть количественных 
показателей выраженности психологического благополучия и счастья студентов разных культур при специфичности качественного наполнения исследуемых феноменов.

\section{Литература}

1. Григоренко Е.Ю. Психологическое благополучие студентов и определяющие его фракторы. Проблемы развития территории. 2009. № 2. c. 98-105.

2. Машарская О.С. Кросскультурные различия социальных представлений студентов о благополучии: автореф. дис., к.пс.н. Курск. 2012.

3. Самохвалова А.Г., Аванесян Г.М., Асриян Э.В. Кросскультурные различия коммуникативных трудностей российских и армянских подростков. Вестник Костромского государственного университета. Серия: Педагогика. Психология. Социокинетика. 2018. № 3. с. 73-83.

4. Фомина 0.0. Факторы и возможные типы психологического благополучия личности. Известия Саратовского университета. Новая серия. Серия Акмеология образования. Психология развития. 2016. Т. 5. №2 (18). DOI: https://doi.org/10.18500/2304-9790-2016-5-2-168-173.

5. Чеботарева Е.Ю. Кросс-культурные особенности копинг-стратегий российских и фрранцузских студентов в контексте психологического благополучия. Известия Саратовского университета. Новая серия. Серия Акмеология образования. Психология развития. Саратов, 2018. c. $156-162$.

\section{PSYCHOLOGICAL WELL-BEING OF RUSSIAN AND ARMENIAN STUDENTS: A CROSS-CULTURAL ASPECT}

The study was carried out with the financial support of the RFBR and the KN RA within the framework of the scientific project No. 20-513-05005 20 Shipova N.S., Rumyantsev Yu.V., Samokhvalova A.G. (Kostroma State University, Kostroma, Russia)

This article presents the results of an empirical analysis of the components of happiness and well-being in accordance with the theoretical and partially empirically verified author's model. The article describes the results of descriptive statistical processing of data from 363 respondents, as well as factor analysis of data on happiness and well-being in two samples: Russian and Armenian students. Comparison of these indicators is also described. As a result, various ideas about psychological well-being that exist among student youth are highlighted. If there are 
similarities in considering well-being as a result and goal of activity (the factor "Wellbeing as a result / activity"), as well as the image of the future (factor "Well-being as a goal"), which a person strives for, students of different nationalities put different ideas into this image. Russians combine family, personal and professional well-being more organically than Armenians. At the same time, Armenians better integrate success in interpersonal and intrapersonal interaction, while Russian students tend to share these parameters. In general, the article illustrates the similarity of quantitative indicators of psychological well-being and happiness in Russian and Armenian students with different qualitative content of the studied indicators.

Keywords: psychological well-being, student age, happiness, life satisfaction, lifemeaning orientations, typology. 